\title{
An Interactive Web-Based Pedagogical Tool for the TRAINING OF ENGINEERS IN ELECTRICAL ENGINEERING
}

\author{
Lyne Woodward, Alexandre H.Limoges, Nicolas Constantin, Sylvie Ratté, and Vahé Nerguizian \\ École de technologie supérieure, 1100 Notre-Dame West, Montreal, Quebec, H3C 1K3 \\ lyne.woodward@etsmtl.ca
}

\begin{abstract}
The electrical engi neering curriculum at ÉTS includes industrial training which introduces interruption periods in the academic training. In addition, as the program contains a broad range of related courses, theoretical concepts need continuous revision and followups by students. Thus, considerable effort is required from the students and professors to review $t$ hese concepts through various courses.

As a solution to this concern, a motivating web-based pedagogical tool has been created. This tool has been used in a linear control course with traditional laboratories and lecturing. The $r$ esults of student satisfaction obtained so far show that this tool is attractive for students and help them in their revision and learning. Moreover, it provides statistics to the professor helping the evaluation of the understanding level of the group through the entire semester.

This paper presents the main features, challenges and results of the web-based pedagogical developed tool.
\end{abstract}

Keywords: e-learning, web-based pedagogical approach, continued training, electrical engineering learning

\section{INTRODUCTION}

The electrical enginee ring curriculum requires the integration of different mathematical backgrounds and fundamental theories. Due to the various courses offered during the curriculum, it happens that some of $t$ hese concepts, not used for a while, may require revision and follow-ups by the students. This need is enforced with the industrial training sessions inserted in the electrical engineering program as it is the case at Éc ole de technologie supérieure. For example, a delay of two years separates two analog electronic $\mathrm{c}$ ourses offered to the students forcing the professors to devote a lot of energy and time to review basic concepts during the fourth year course. Moreover, it may also be difficult for professors to rapidly identify the level of understanding of their students regarding these basic concepts.

As a so lution to this concern, high quality revision material was developed under Microsoft Excel for these electronic courses [1]. Howeve $r$, this existing platform showed a certain level of inefficiency based on different criteria such as accessibi lity, user friendline ss and statistical treatment of the results. Since ith as been demonstrated that blended learning induced by eLearning techniques brings a noticeably improvement in engineering studies [2], the need to create a motivating web-based pedagogical tool was identified at ÉTS, and is the object of an institutional research funding.

This project contributes to improving the efficiency of the existing tool by:

- Developing a web-based interface accessible from the intranet of ÉTS

- Developing additional revision material for other courses

- Including statistical analysis of the evaluation results providing stud ent's self-evaluating means

- Providing feedback to professors about the progression of their students.

This project also contributes to the improved performance of the web-based tool AARTIC (from the French: Apprentissage, Adaptatif, Repère, Technologie de l'Information et des Communications), developed by the software engineering and IT department at ÉTS [3]. The completion of the new platform along with a fi rst application in a lin ear control course sh owed its promising efficient potential.

The paper is organized as follows. In section 2, the main features of $t$ he web-designed pedagogical tool are presented. The pedagogical approach used to introduce the tool in the class is resu med in section 3. Finally, section 4 gives conclusions and recommendations.

\section{MAIN CHARACTERISTICS OF THE TOOL}

One major limitation of the existing tool developed under Excel was the in terruptions required for updates. To overcome this problem, the web-based pedagogical tool is developed under client-server architecture (Fig. 1). Hence, a continuous communication is guaranteed and the need to download the application each time an action i $\mathrm{s}$ 
performed by the use $r$ is eliminated. The web interface is built using PHP language along with the jQuery library. The "HighCharts" library is also used to produce the graphs of the statistics section. All the data included in the application are stored in a database (MySQL) hosted by the computer department at ÉTS.

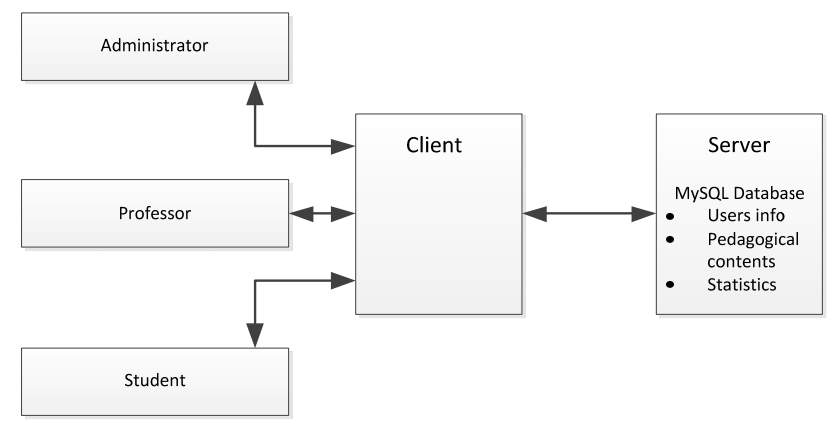

Fig. 1. Structure of the web-based tool

This tool can be accesse d by three different user profiles, each of them having their own privileges as listed below:

- Administrator:

o add or delete users (either professors or students)

o create or change their passwords

o form groups of students for each class

- Professor:

o change and organize the pedagogical content

o view the statistics on the frequency of use of the tool by a group of students and the results obtained to the autoevaluation
- Student:

o evaluate himself by ans wering the questions

o view the statistics and d epict his performance to the questionnaires

\subsection{The professor interface}

The pedagogical content developed by the professors is linked to each course and is classif ied following a predefined hierarchy composed of levels, themes, subthemes and questions. The professor can fully develop the levels and make them visible to the students at the moment of his choice during the semester. Three types of questions can be developed:

- Multiple choice questions

- True of false questions

- Short answers questions.

When defining a new question, the professor identifies the true answer and links it to a sho rt explanation or an example in order to provide real-time feedback to the students during their auto-evaluation (Fig. 2). The professor can visualize the questions as they will app ear to the students. At any moment during the semester, the professor can visualize the statistics on the frequency of use of a group (Fig. 3) and the results obtained by the students for a particular theme or su btheme (Fig. 4). Furthermore, history is available for the first and the last try of the students. An analysis of these statistics by the professor is very useful to identify theoretical concepts that are clearly understood or not by the students. The professor can then inform the students about this analysis and enforce some concepts during the lecturing in the class.

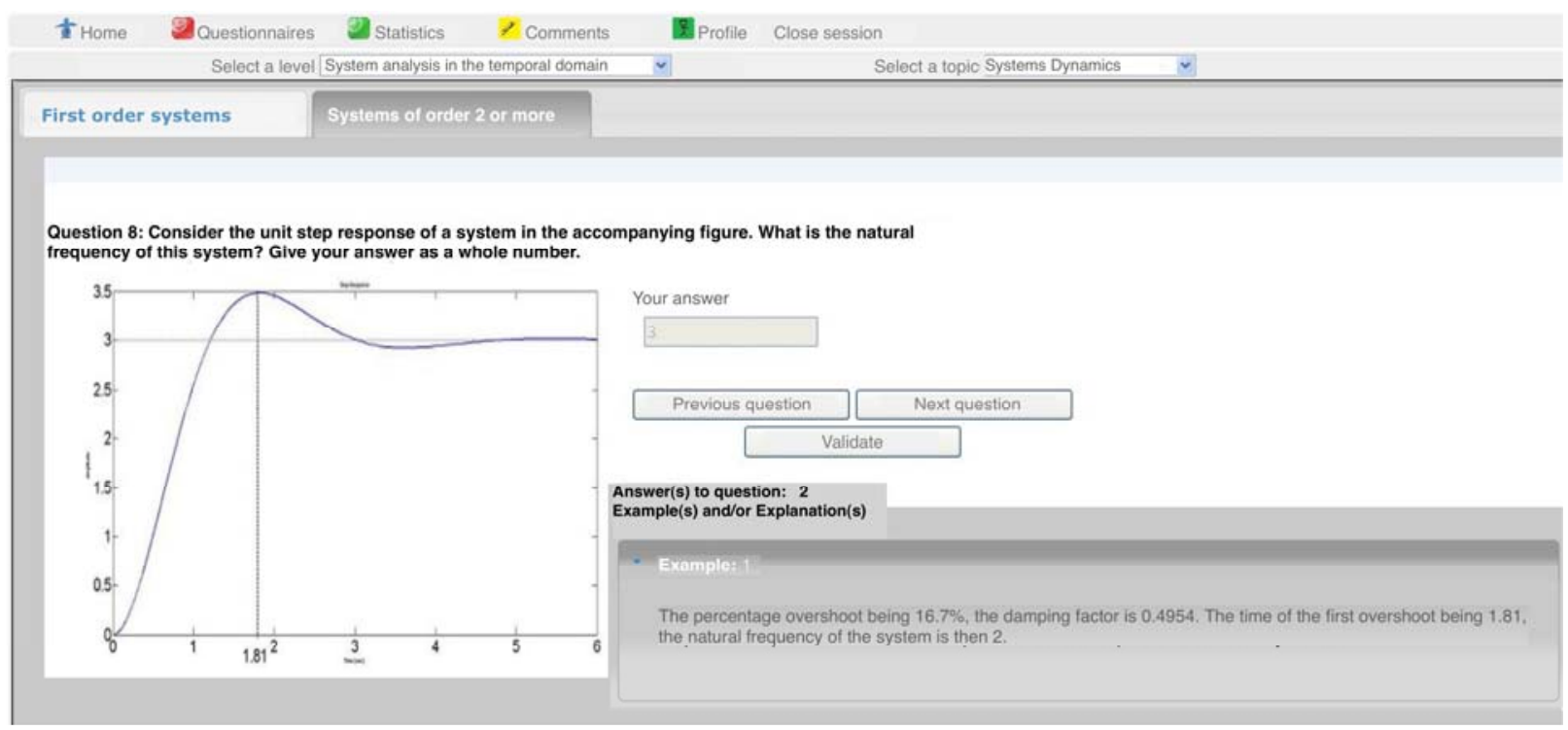

Fig. 2. Example of a question in the student environment 


\subsection{The student interface}

When the student enters the web-based pedagogical tool, he/she first chooses the course for which he/she wants to practice. Then, he/she can access the que stions by first selecting the level, the theme and subtheme of his/her choice. Once he/she has answered a question, he/she can validate the given answer and read the ass ociated explanation prior to continue the questionnaire. Thus, clear online feedback is provided in order to overcome weak points as recommended in [4]. Once a questionnaire is completed the student obtains his/her score. Statistics on the results are also acces sible to the students by the provided tool to monitor their progression by comparing scores obtained for each try (Fig. 4).

\section{APPLICATION IN CLASS: PEDAGOGICAL APPROACH}

The tool was used for the first time in 2 groups of linear control course (ELE275-asservissements linéaires) of the department of electrical en gineering at ÉTS during the winter 2012 semester. For this course, 85 questions were generated and organized in 4 levels, 8 themes or topics and 12 subthemes or sub-topics. For the first attempt, the tool was used on a voluntary basis: students were invited to use the web-based pedagogical tool to practice and review the theoretical concepts through the entire semester. The statistics on the frequency of use (Fig. 3) show that the students mainly used the tool to review the topics covered in class before the quiz and the exams. Thus, higher frequency of use was observed at weeks 5, 7, 10 and 14 which corres pond respectively to the weeks preceding quiz 1, mid-term exam, quiz 2 and final exam. At the end of the sem ester, a survey was conducted among the users of one group. Among the survey respondents, $78 \%$ agreed to say that the we b-based pedagogical tool has a great potential for their learning. Comments were $\mathrm{p}$ rovided to extend the pedagogical content and add new questions on a more frequent basis during the semester. Through these comments, a good receptivity from the users was observed.

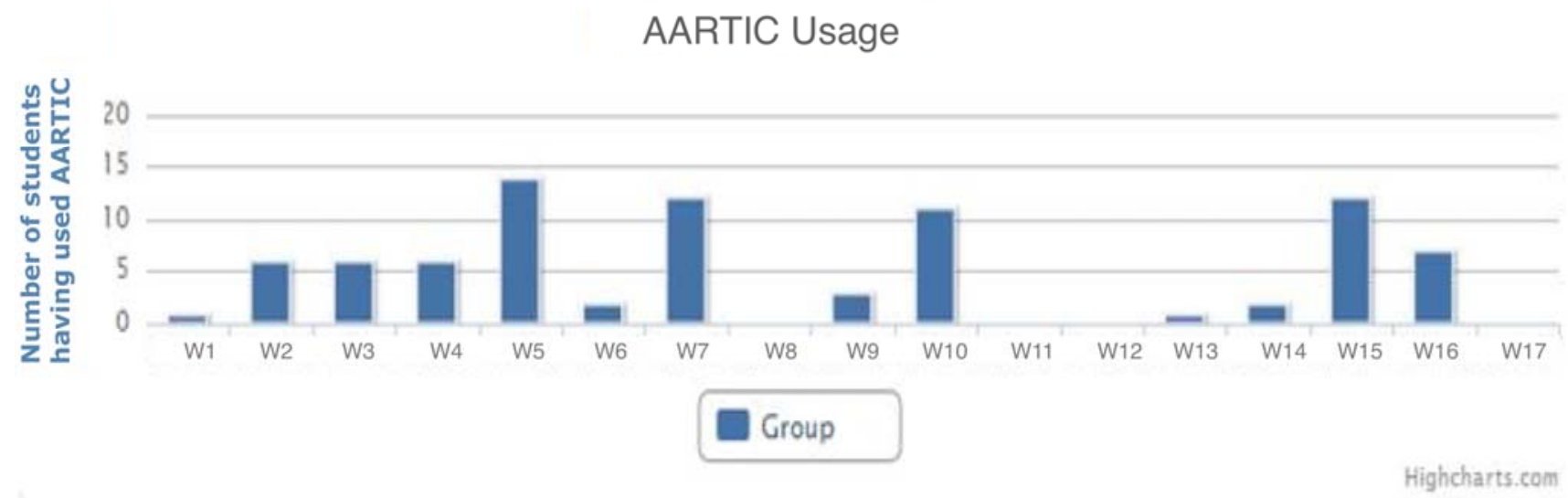

Fig. 3: statistics provided to the professor on the frequency of use of a group

In a pedagogical context, the web-based tool has many advantages:

- Responsibility for stud ents to consolidate their learning

- Transferability of the web-based pedagogical tool to other courses of different departments

- Dynamic pedagogical content which can easily evolve through semesters

- $\quad$ Real-time feedback provided both to professors and students
The main disadvantage of this is the necessity to provide to the users instan taneous software su pport both for the development and $\mathrm{t}$ he use of $\mathrm{t}$ he tool all along the semester. From this first experience in class, it wa $\mathrm{s}$ observed that temporary connectivity problem could be a major obstacle to the motivation of the students using this tool. 


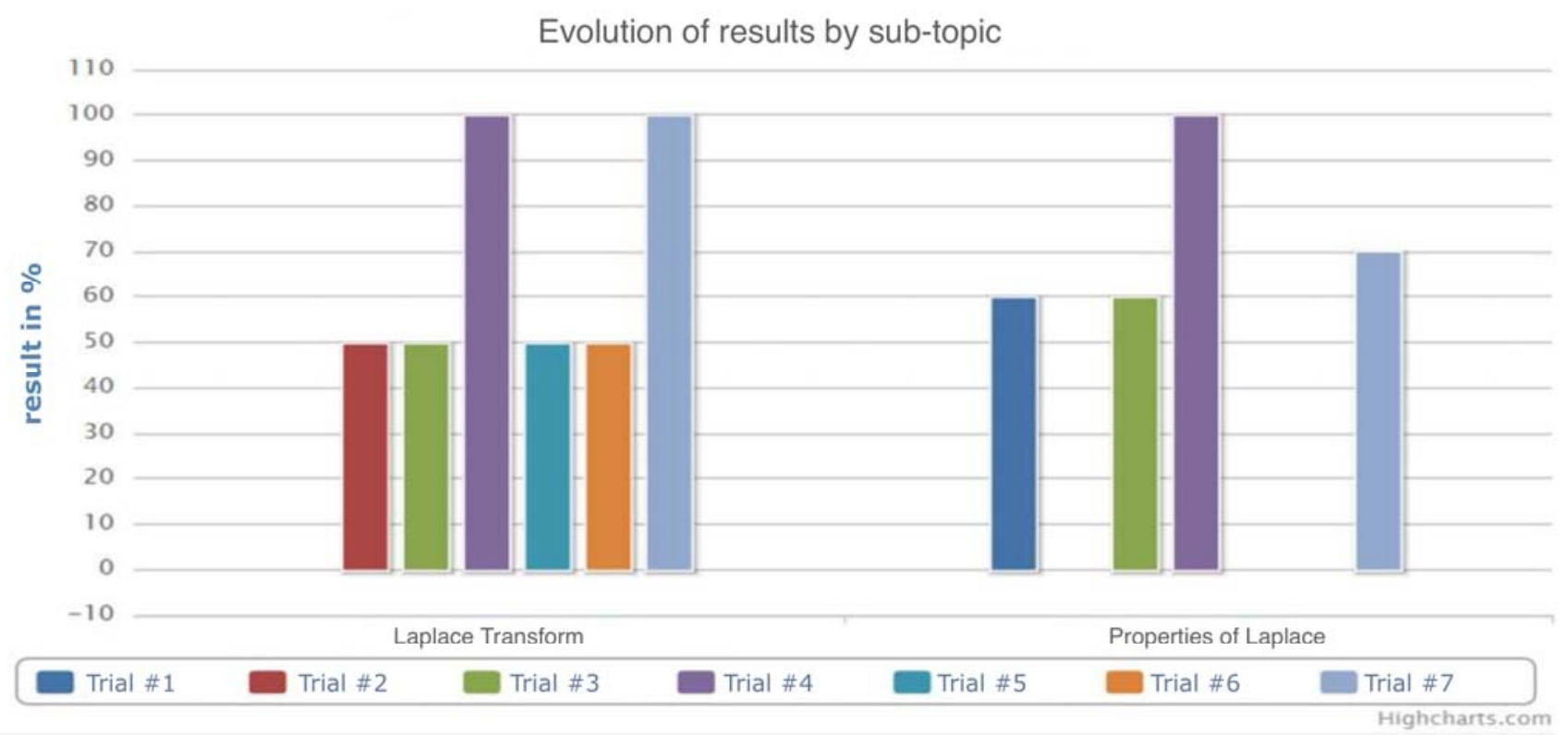

Fig. 4. Example of statistics provided to students on the results obtained to each auto-evaluation

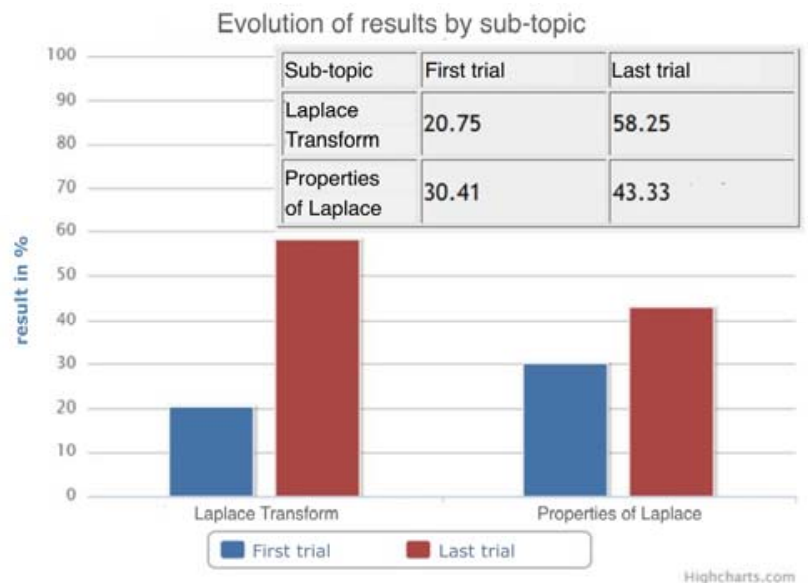

Fig. 5: Statistics provided to the professor on the results obtained by a group on a particular theme

\section{CONCLUSIONS}

An electrical engineering curriculum contains several courses having some common theoretical concepts. The review of these concepts in class re quires a bi $\mathrm{g}$ investment at the beginning of a course and reduces the available time to introduce new theoretical concepts. To overcome this problem, a web-based pedagogical tool was built and used in a class of linear control course of the department of el ectrical engineering at École de technologie supérieure during the semester of wi nter 2012. The tool offers real-time feedback to the students about the good answers to the questions asked and measures the learning evolu tion of $t$ heir performances. The professors also obtain feedbac $\mathrm{k}$ about the learni ng progression of their students. This feedback gives them clear objectives about som e subjects that shoul d be emphasized during the in clas s lecturing. The results of a survey conducted among the students who used the tool show its real importance and benefit to the students. Thus, future work will focus on the application to other courses of the electrical department of ÉTS and also to other departments. More evaluation of the tool will be assessed by identifying learning performance with and without this tool.

\section{Acknowledgements}

The authors would like to acknowledge the support of École de $\mathrm{t}$ echnologie supérieure by "the program of institutional support in research and in education (PSIRE)".

\section{References}

[1] Nicolas Constantin, Guy Ayissi Eyebe, and Vahé Nerguizian, "A New Pedagogical Tool for the Training of Engineers in Analog Electronics," in Proc. CEEA Canadian Engineering Education Conf., CEEC10, Andy Fisher (ed.) (Kingston, ON; 7-9 June 2010), 1 p., 2010.

[2]Martin Uren and James Uren "eTeaching and eLearning to enhance learning for a diverse cohort in engineering education," Engineering Education, vol. 4, no. 2, 2009.

[3] Faten Mhiri, and Sylvie Ratté, "AARTIC: Development of an Intelligent Environment for Human Learning," in Proc. 14th annual ACM SIGCSE Conference on Innovation and Technology in Computer Science Education, ITiCSE09, (Paris, France; 6-9 June 2009), 1 p., 2009.

[4] Sofia M. Dopper and Ellen Sjoer "Implementing formative assessment in engineering education: the use of the online assessment system Etude," European Journal of Engineering Education, vol. 29, no. 2, June 2004. 